\title{
"Remar o próprio barco": a centralidade do trabalho no mundo das mulheres "sós""
}

\author{
Eliane Gonçalves ${ }^{* *}$
}

\begin{abstract}
Resumo
Várias das noções atribuídas às mulheres "solteiras" presentes na teoria social e no senso comum remetem a algumas idéias proclamadas pelo feminismo. Educação, trabalho qualificado $e$ remunerado são considerados a via privilegiada para a conquista da "autonomia" que, ampliada, possibilitaria a um conjunto de mulheres, sobretudo das camadas médias urbanas, maiores chances de realizar escolhas, decidir por si mesmas e até mesmo romper com os estereótipos clássicos da "solteirona". Compreender como se entrelaçam as noções associadas à idéia de "mulher independente" e seus paradoxos requer revisitar algumas idéias que marcaram a emergência e a consolidação do feminismo como um movimento político da "modernidade" em sua expansão a partir dos anos 1960. Neste artigo, examino os nexos entre educação e profissionalização e o não casamento na contemporaneidade, a partir da análise de algumas narrativas de mulheres "solteiras" de camadas médias urbanas, sem filhos e que moram sozinhas.
\end{abstract}

Palavras-chave: Gênero, Feminismo, Trabalho, Solteiras, Casamento.

\footnotetext{
"Recebido para publicação em agosto de 2008, aceito em abril de 2009. Este artigo foi elaborado a partir de minha Tese de doutorado "Vidas no singular: noções sobre mulheres 'sós' no Brasil contemporâneo" (2007), orientada por Adriana Piscitelli. Agradeço a Iara Beleli pelos comentários e correções.

** Doutora em Ciências Sociais, professora da Faculdade de Ciências Sociais da Universidade Federal de Goiás. elianego@uol.com.br
}

cadernos pagu (34), janeiro-junho de 2010, 235-268. 
"Remar o próprio barco"

"Rowing One's Own Boat":

The Centrality of Work in the World of Single Women

\begin{abstract}
Several notions attributed to single women in social theory and in the common sense refer to some ideas proclaimed by feminism. Education and qualified, paid work are considered the privileged path to conquering autonomy. When broadened, this autonomy would allow a set of women, mostly those from the urban middle classes, greater opportunities to make choices, to make decisions by themselves and even to break with the old stereotypes of "spinsters". To understand how notions associated with the "independent woman" and their paradoxes are intertwined requires a review of some ideas that marked the emergence and the consolidation of feminism as a political movement of "modernity" in its expansion from the 1960s on. In this article, I examine the connection between education and professionalization and non-marriage in the present day, taking into account narratives of middle class, childless single women living alone.
\end{abstract}

Key Words: Gender, Feminism, Work, Single Women, Marriage. 
Uma mulher que não tem medo dos homens, amedronta-os.

Várias das noções atribuídas às mulheres "sós" presentes na teoria social $e$ no senso comum remetem - positiva ou negativamente - a algumas idéias proclamadas pelo feminismo, sendo a experiência de morar só mesclada às noções da "nova solteira" ou da mulher "independente", "livre" e "moderna". Nesse cenário, educação, trabalho qualificado e remunerado são considerados a via privilegiada para a conquista da "autonomia" que, ampliada, possibilitaria a um conjunto de mulheres, sobretudo das camadas médias, maiores chances de realizar escolhas, decidir por si mesmas e até mesmo romper com os estereótipos clássicos da "solteirona". De certo modo, essas noções evocam a preocupação de Virgínia Woolf (1985) no início do século XX, com a falta de autonomia das mulheres de seu círculo, na Inglaterra, em A room of one's own, atribuindo grande importância à renda anual própria $e$ ao espaço para o desenvolvimento de um trabalho criativo, emoldurado na idéia do quarto para si.

Essa autonomia conquistada é também frequentemente apresentada como conflitante com o os interesses da vida matrimonial e grande ênfase é concedida ao desencontro entre "velhos homens" e "novas mulheres". Esse aparente paradoxo (quase um clichê) é recorrente nos discursos da mídia e emerge nas falas de mulheres de camadas médias, escolarizadas e com carreiras estabelecidas. Contudo, ele tem recebido pouca atenção de estudiosos/as feministas, que tendem a olhar o fenômeno sob a rubrica estrita de um gender gap. ${ }^{1}$

1 A expressão gender gap é recorrente em artigos acadêmicos e da mídia quando comparam indicadores sociais para ambos os sexos enfatizando as desigualdades. O termo vem sendo utilizado para referir-se às conquistas feministas que emanciparam as mulheres deixando os homens em descompasso. Optei por utilizá-la em inglês, mas uma tradução simples seria hiato, que 
"Remar o próprio barco"

Compreender como se entrelaçam as noções associadas à idéia de "mulher independente" e seus paradoxos requer revisitar algumas idéias que marcaram a emergência e a consolidação do feminismo como um movimento político da "modernidade" em sua expansão a partir dos anos 1960. Neste artigo, examino os nexos entre educação e profissionalização e o não casamento ${ }^{2}$ na contemporaneidade, a partir da análise de algumas narrativas de mulheres "solteiras" de camadas médias urbanas, sem filhos e que moram sozinhas.

\section{Gênero, feminismo e trabalho - algumas aproximações}

Relações de trabalho representam um aspecto das relações sociais marcadas por gênero, sendo um lócus importante daquilo que é definido como masculino e feminino (Lobo, 1992) e é no mundo do trabalho que homens e mulheres se enfrentam como indivíduos aparentemente livres e iguais (Durham, 1983:35). Estudos antropológicos de inspiração feminista apresentam a divisão sexual do trabalho como universal, ressaltando a dominância das atividades em termos de poder e prestígio associadas ao masculino (Rosaldo, 1979). Nas sociedades industrializadas e capitalistas contemporâneas, nas quais autonomia e prestígio dependem da circulação de capital, a independência financeira é extremamente relevante (Millet, 1970). A busca por individualização e a independência financeira dependem cada vez mais do emprego assalariado (Gordon, 1994), razão pela qual, nessas sociedades, a reivindicação feminista por equivalência em termos de emprego e salário continua ainda tão atual.

traduziria em números ou valores simbólicos a distância entre homens e mulheres na sociedade em qualquer esfera.

2 Embora a pesquisa inclua mulheres de diversas trajetórias afetivas e sexuais, suas narrativas não aparecem identificadas com a categoria "orientação sexual", a análise recai sobre o casamento em sua forma heterossexual "tradicional". 
Segundo Nicholson (1986), o direito ao trabalho é uma noção presente em todas as correntes do feminismo da segunda onda. ${ }^{3}$ A vertente liberal influenciou mais diretamente a luta por direitos na esfera pública, ao condicionar a superação da subordinação da mulher à obtenção de direitos no plano formal, particularmente a conquista de oportunidades de treinamento $e$ profissionalização. Se para as feministas radicais o trabalho não era menos importante, a discussão levantava questionamentos políticos mais desestabilizadores - ruptura com a norma heterossexual, fim do contrato de casamento, crítica à família, controle sobre o corpo, maternidade como escolha voluntária, entre outras. De modo geral, mas em diferentes escalas, as feministas da segunda onda criticavam e recusavam a separação das esferas pública/privada e suas dicotomias fundadas na diferença sexual.

Friedan (1963) proclamava que o trabalho formal remunerado, fora de casa, numa gama ampla de opções acompanhadas de treinamento profissional - daria às mulheres condições iguais de relacionamento que seriam bem-vindas no "todo" social. Nas formulações - mais programáticas que teóricas - do feminismo liberal, o mundo público (masculino, criativo, objetivo) não é submetido à crítica e é pensado em oposição ao mundo privado (feminino, subjetivo, enfadonho). A crítica à separação das esferas é pautada por uma noção que enfatiza as transformações do mundo privado como forma de oferecer à mulher oportunidades iguais no mundo público, superando o "mal que não tem nome", característico do confinamento doméstico. Desatentas a alguns importantes significados culturais

3 O feminismo costuma ser dividido em duas ondas: a primeira, que vai do final do século XIX ao fim da Segunda Guerra Mundial. A segunda onda se inicia no final dos anos 1960, quando, de fato, se produz uma tentativa de teorizar a opressão da mulher (Rupp, 2002). A partir dos anos 1980, emergem as teorias críticas à segunda onda e ganham relevância os estudos de gênero (Piscitelli, 2002; Simpson, 2005). Há quem aceite a existência, embora controversa, de uma terceira onda identificada como pós-feminismo. 
"Remar o próprio barco"

de gênero, as formulações eram obviamente endereçadas a mulheres de camadas médias que, como Friedan, eram casadas, possuíam formação superior e almejavam certa independência.

\section{A centralidade do trabalho}

Os estudos de modos de vida contemporâneos em sociedades complexas consideram que as identidades sociais dos indivíduos são, em grande medida, construídas mais expressivamente nos domínios do trabalho do que nas relações de família e de parentesco (Velho, 2002), insinuando novas e diferentes perspectivas relacionais. A rápida mudança nas relações sociais, sobretudo o padrão "homem provedor/mulher cuidadora" que modelava a "família nuclear", é apontada como o elemento central que explicaria como o trabalho se tornou fundamental na vida de uma parte considerável das mulheres nas "sociedades ocidentais" na contemporaneidade.

Ainda assim, para algumas mulheres profissionalizadas de camadas médias e altas, casadas, unidas, ou vivendo com a família, o salário pode ser considerado parte do orçamento doméstico ou um "complemento" ao salário do marido ou da família. Não é o caso das mulheres que entrevistei ${ }^{4}$, para as quais o salário é responsável pela totalidade das despesas domésticas e extra-domésticas. No universo das entrevistadas, o trabalho emerge como uma categoria marcante, tanto como ocupação, emprego, em diferentes fases da vida, como também profissão, carreira. Ainda que não seja o único fator, todas afirmam a importância do trabalho remunerado na viabilização da escolha de morar só. A maioria das entrevistadas começou a ter uma

4 Entrevistei 12 mulheres de camadas médias, solteiras, sem filhos, com idades entre 29-53 anos, com diversas carreiras profissionais, morando sozinhas em Goiânia, Goiás, no período de 2003 a 2005. Trata-se de um grupo heterogêneo em termos raciais, geracionais, religiosos, de origem (geográfica e de classe) e de orientação sexual. As marcas de raça/cor mencionadas no artigo foram autodeclaradas. 
renda própria antes mesmo de terminar a faculdade, mostrando que o trabalho, a existência da profissão em contextos contemporâneos, organiza ou influencia - para não dizer que determina - outras esferas da vida das mulheres de camadas médias, particularmente as que moram sós.

As primeiras oportunidades formais de trabalho abertas às mulheres se concentravam em funções de baixo prestígio e com jornadas extenuantes. Embora o problema ainda persista nas camadas populares - o que é válido também para o Brasil -, o gradual e constante aumento na escolarização, a partir dos anos 1960, abriu perspectivas inteiramente novas às mulheres de camadas médias, além de permitir certa mobilidade social. Como observa Sarti, analisando as relações entre gênero, trabalho $e$ classe no Brasil, o considerável aumento da participação feminina no mercado de trabalho nas duas últimas décadas não teve o mesmo impacto sobre todas as mulheres, atingindo, sobretudo, as que se beneficiaram da expansão do sistema educacional:

As mulheres pobres, por outro lado, sem acesso à educação de nível médio e superior, mantiveram suas condições estruturais de participação no mercado de trabalho, cuja expansão não configurou necessariamente, em seu caso, uma situação nova, que abalasse os fundamentos das relações na família (Sarti, 1997:154).

De modo diverso, mulheres que tiveram acesso à educação $e$ à profissionalização puderam trilhar caminhos antes negados ou restritos a poucas. Aparentemente, todas as profissões foram conquistadas, embora a presença de mulheres em carreiras consideradas "femininas" - serviço social, saúde, ensino/ educação, etc. - ainda sejam dominantes (Rosemberg, 2001; Lobo, 1992; Bruschini, 2000). Segundo Bruschini e Puppin (2004:108), "a expansão da escolaridade, à qual as brasileiras têm tido cada vez mais acesso, é um dos fatores de maior impacto sobre o ingresso das mulheres no mercado de trabalho". 
"Remar o próprio barco"

Estudos feministas focalizando "solteiras" em grandes cidades do mundo (Trimberger, 2005; Simpson, 2003, 2005; Byrne, 2000; Gordon, 1994;) têm chegado a uma mesma conclusão: "solteiras" sem filhos costumam investir tempo e energia no trabalho e como quase sempre são muito mais qualificadas têm rendimentos superiores. No Brasil, as pesquisas relativas ao mercado de trabalho apresentam resultados semelhantes. Comparando indicadores da década dos 1990 com os anteriores, Bilac (2002:5) argumenta:

Num flagrante contraste com as situações anteriores, a melhor situação laboral feminina é encontrada entre as mulheres jovens $e$ adultas que moram sozinhas: elas apresentam altas taxas de participação com menores taxas de desemprego e níveis mais elevados de rendimentos. Mas é muito provável que apenas o fato de morarem sozinhas já identifique uma inserção diferenciada no mercado de trabalho - de maior qualificação, maior formalização $e$ estabilidade -, que interfere na trajetória de vida, uma vez que, em função de uma carreira profissional, projetos podem ser postergados ou abandonados.

Embora não façam distinção entre "solteiras" e mulheres que moram sozinhas, Bruschini (2000) e Néri (2005) chegam a conclusões semelhantes: mais anos de estudo e tempo para dedicação prioritária ao trabalho é uma realidade crescente entre as "solteiras" sem filhos, notadamente as que exercem ocupações técnicas e científicas de maior prestígio.

O feminismo produziu uma crítica profunda aos modelos calcados na divisão entre trabalho produtivo e reprodutivo e à divisão sexual do trabalho, que condena as mulheres a ofícios $e$ tarefas associadas à sua "natureza" (Daniele Kergoat, 2002). Assim, herdeiras dessa "revolução", a maioria das entrevistadas, particularmente as mais jovens, não enfrentou grandes desafios na escolha profissional, pois, aparentemente, todas as portas já se encontravam abertas a elas. 
Eliane Gonçalves

\section{Letramento e acesso à educação}

O letramento ${ }^{5}$ tem funcionado como uma porta de acesso ao conhecimento, abrindo caminhos a outros vôos, como observaram as entrevistadas nos relatos sobre suas infâncias repletas de referências escolares e literárias, cuja influência é atribuída predominantemente a mães e pais. Como assinala Vaitsman (1994:92), a partir dos anos 1960, no Brasil, os/as pais/mães orientavam as filhas para os estudos, o casamento e a profissionalização, nesta ordem. Entretanto, os planos de estudar e trabalhar eram complementares ao casamento, não seu substituto.

Rompendo com uma tradição histórica desde que as mulheres conquistaram o direito de estudar, nenhuma entrevistada cursou escola normal ou foi professora primária. Como ilustram Corrêa (2001) e Vaitsman (1994), a passagem pela Escola Normal era comum a uma geração de mulheres que prosseguiu nos estudos universitários no Brasil dos anos 1960. Porém, se a escola normal não foi lugar de passagem de nenhuma das entrevistadas, cinco encontraram na docência um caminho comum, confirmando uma tendência de crescimento da participação das mulheres também no magistério superior (Rosemberg, 1992; 2001). A correlação entre magistério, profissão "feminina" e "solteirice" foi analisada por Louro (1997), enfatizando a ambiguidade que cercava a professora "solteirona" como mulher que fracassara no seu destino de esposa e mãe, mas que, por outro lado, tinha assegurada sua independência econômica que lhe permitia circular publicamente, usufruindo de alguns privilégios "masculinos". Já a pesquisa de Nádia Amorin com mulheres "solteiras" em Maceió mostra que, das 66 mulheres

5 Letramento é um conceito mais político que técnico e ultrapassa a idéia de escolaridade. Pinto (2004) afirma que ler, no sentido de decifrar e praticar a codificação de letras, não significa letramento, que deve ser compreendido numa perspectiva histórica, levando-se em conta as estruturas de poder e não os indivíduos, e que permita explicar, por exemplo, a dificuldade declarada pelas mulheres com alto grau de escolarização para produzir textos escritos a serem publicados. Sobre letramento, cf. Kleiman, 1995. 
"Remar o próprio barco"

entrevistadas, $50 \%$ eram professoras - "a mulher que não casava tinha que virar professora" (Amorin, 1992:84).

A importância do estímulo dos pais/mães para o letramento é relatada por Helena, 44 anos, professora universitária, branca, ao afirmar seu desejo de publicar as histórias que cultiva desde a infância, período no qual a mãe também a estimulava a aprender as "prendas domésticas" e, ao mesmo tempo, comprava para ela e os irmãos grandes coleções "vendidas de porta em porta".

Minha mãe dizia que o primeiro piolho que ela matou na minha cabeça ela matou num jornal para eu aprender a ler... [risos]. Como eu vivia com um livro andando para baixo e para cima, ela dizia assim "ah... tenho grande arrependimento de ter feito isso, porque eu devia ter matado esse primeiro piolho na máquina de costura, assim você seria costureira".

Como afirma Gordon (1994:57), frequentemente, pais/mães endereçam mensagens contraditórias às suas filhas. As mães, sobretudo, encorajam a educação escolar e a busca do autosustento $e$, ao mesmo tempo, enfatizam a importância de serem competentes como esposas e donas-de-casa. O "arrependimento" da mãe de Helena evidencia a ambivalência no contexto de uma família considerada tradicional numa cidade do interior, cujas preocupações com as filhas também incluíam a preparação para a função de esposa, mãe e "dona-de-casa prendada". Ainda neste período (1960/70), as mulheres eram retratadas, sobretudo, como mães dedicadas, esposas femininas e bondosas ou candidatas prendadas. A análise de Bassanezi (2000) da representação da mulher burguesa nos anos 1950 mostra a recorrência do protótipo da "moça casadoira" nas revistas femininas. Helena discorre, com certo orgulho, ao longo da entrevista, de suas prendas - cozinhar, marcar e bordar - porque pode, seletivamente, realizá-las nas horas livres, como lazer. Ao ampliar seu leque de possibilidades e, consequentemente, sua opção de escolha, aquilo que outrora era obrigação passa a ser cultivado como prazer. 
A educação ou o investimento na vida escolar e acadêmica, em detrimento de outras esferas da vida, marca de modo definitivo as escolhas dessas mulheres, assim como a entrada no mundo do trabalho e a responsabilidade pela tomada de decisões. Dessa forma, estudo e profissionalização funcionam como verdadeiros arsenais contra a dependência feminina.

Muitas mensagens, "arquivadas" da infância, se relacionam à curiosidade intelectual $e$ ao deslumbramento com as descobertas proporcionadas pela leitura. Essas memórias, carregadas de afeto durante as entrevistas, foram arroladas como explicação parcial do relativo desinteresse pelo casamento. Camila, 43 anos, psicanalista, negra, conta que foi alfabetizada pelo pai em casa e que a existência cercada de livros facilitou, desde cedo, a exploração da leitura. Como seu pai alfabetizava as empregadas domésticas, ela ficava "ali ao lado" e, desse modo, entrou na escola já sabendo ler e escrever. Sua "inquietação" pelo conhecimento está associada à sua infância partilhada com outras crianças que também gostavam de ler, influência esta que ela considera decisiva para a escolha dos dois cursos superiores que fez.

Laura, 47 anos, professora universitária, branca, enfatiza a grande curiosidade que a acompanhou desde cedo:

eu, desde pequena, queria ser cientista, pesquisadora, sabe, eu nunca quis ser mãe (...) Eu não sou um poço de inteligência, porque minha inteligência é absolutamente normal, mas sempre quis estudar, você entende?

Madalena, 42 anos, relações públicas, branca, realça a aprendizagem vivida fora dos limites da casa paterna/materna:

No meu caso, eu fui morar em Paris nove meses, acabei ficando muito mais tempo e, quando eu terminei de fazer minhas escolas lá, meus estudos..., foi minha primeira experiência fora da minha família e foi uma experiência fantástica, eu acho que tudo o que eu sou em nível cultural, 
"Remar o próprio barco"

foi porque eu morei em Paris, eu tive chance de viajar o mundo inteiro, eu fui bem sucedida como brasileira lá fora, eu fui por que eu queria estudar.

Se a curiosidade intelectual marca de modo particularmente positivo as narrativas, a noção de independência pela via do trabalho apresenta sentidos muitas vezes contraditórios. Algumas entrevistadas expressam orgulho e elevada consideração por si mesmas naquilo que fazem $e$, ao mesmo tempo, sentem-se ameaçadas pela competitividade do mundo público; são confiantes em sua capacidade de "gerenciar a própria vida", mas explicitam suas "carências" e desejo de proteção. O exercício profissional aporta doses consideráveis de prazer e realização, mas também produz cansaço, desgaste, exaustão, tornando necessário encontrar "um tempo para si". A relação com o dinheiro pode ser extremamente calculada e planejada ou ser percebida como um total descontrole. De um lado, a independência financeira pode ocasionar um tipo específico de dependência em relação a figuras masculinas - pai ou um irmão -, de outro, é referida em termos positivos - "sou dona da minha vida", "não tenho de engolir sapos", "não devo nada a ninguém". Mas são igualmente recorrentes expressões que sinalizam certa ambiguidade - "minha independência afastas os homens, eles têm medo de mulheres como eu". No entanto, a independência física, mental $e$ emocional, que as tornam auto-suficientes, na dubiedade das falas, aparece diluída ante a ameaça do adoecimento e do envelhecimento - ser velha é não poder mais trabalhar.

\section{Ter dinheiro, ganhar a vida - significados do trabalho}

A entrada em massa da mulher no mercado de trabalho altera, necessariamente, a própria noção de trabalho. O trabalho é de tal modo pensado no masculino que fala-se em "feminização" quando as mulheres acendem a posições historicamente dominadas pelos homens e pode tanto ser retratada como 
conquista das mulheres no campo da igualdade, como perda de prestígio daquela profissão (Picot, 2002).

A relação entre mulher e trabalho tem sido analisada de modo a privilegiar a dupla jornada, os baixos salários, a disparidade salarial e a questão da díade produção/reprodução no sistema capitalista (Prisca Kergoat, 2002). Nesse sentido, as análises estão predominantemente focadas na exploração, nos sacrifícios $e$ nas perdas e menos no significado de realização e satisfação advindas do exercício de uma profissão. Ao enfatizar majoritariamente a divisão sexual do trabalho e suas implicações na vida de mulheres casadas e mães, Gordon (1994) afirma que estudos centrados na relação mulher e trabalho negligenciam análises que levam em conta a posição das não casadas, para as quais a entrada no mundo do trabalho tem uma função de ritual de passagem semelhante ao do casamento, pois opera uma mudança significativa no modo de vida, constituindo boa parte do sentido de identidade dessas mulheres. Ao mencionar como é afetada pelo prazer advindo do trabalho, Camila relata:

Tem uma coisa que mexe muito, estudar, no caso atender, o exercício da minha profissão, hum, olha não tem orgasmo melhor, [risos], é muito prazeroso. Eu tenho um amor profundo por aquilo que eu faço, isso me mobiliza, mexe comigo assim, de ponta a ponta. (...) Muita vezes, o que é considerado pesado pro outro, pra mim não é, é prazeroso, porque como dá prazer, quer dizer, estudar, ler, escrever, desenhar, montar projetos, ir pra prática, isso me é extremamente prazeroso. Escutar, no consultório, isso me é o sol. Então, acho que isso alimenta muito a minha vida, é o meu alimento.

É interessante notar que esta fala de Camila ocorre numa seqüencia na qual ela está discorrendo sobre o quanto a sociedade acha estranho uma mulher que não quer ter filhos, que não se "mobiliza" em função da maternidade, porque o que a "mobiliza" mesmo é sua profissão de psicanalista. O sentimento 
"Remar o próprio barco"

de Camila se assemelha ao de Helena, que se refere de modo particularmente carinhoso às suas relações com os alunos que orienta. Ela considera "amigos" porque "transcenderam os limites" da relação formal professora/aluno e fala da relação com esse trabalho de modo vibrante:

(...) dar aulas, fazer pesquisa, o contato com os alunos..., é uma satisfação muito grande ver meus orientandos fazerem um bom trabalho, adoro ter esta relação com a escrita, um texto bem feito, isso me causa um prazer, uma satisfação que é até quase físico [risos]. É muito bom isso!

Algumas vezes, a sensação de prazer é acompanhada de uma alta apreciação de si mesmas enquanto profissionais, um sentido que parece compensar a falta de atributos "femininos" socialmente valorizados, mostrando que a superação de barreiras de classe, gênero $e$ "raça" produz uma auto-imagem positiva $e$ forte.

Eu faço o que eu gosto, eu lutei pra fazer o que eu gosto $e$ eu sou boa no que eu faço, tá? Então, eu tenho assim, sem nenhuma vaidade, eu não sou de ficar toda hora colocando isso pra todo mundo, eu sei que eu sou boa no que eu faço, pelos retornos que eu tenho, eu sou uma pessoa que, no Brasil, só eu estudo o que eu estudo (Évora, pesquisadora, negra, 44 anos).

No ramo executivo, é comum encontrar mulheres mais jovens e sem filhos (Bruschini e Puppin, 2004) e são altas as exigências para as que "conseguem" chegar a altos postos nas corporações $e$ instituições públicas e privadas. Convidada para uma entrevista em uma instituição financeira multinacional, Sarah, 29 anos, executiva financeira, branca, sentiu-se desafiada, com medo, mas disposta a viver o desafio: 
Prá mim seria um desafio do tipo "oh, você pode, você tem de tentar" e foi o que eu fiz, acho que fui muito corajosa, eu fui aprendendo com o tempo. Eu achava tudo difícil, tudo para mim era difícil, a palavra que mais saía da minha boca era difícil, hoje eu risquei do meu dicionário, hoje ela não existe mais.

Num mundo simbólica e objetivamente marcado por gênero, algumas mulheres se vêem diante de outros desafios que também contribuem para moldar suas subjetividades. Mariah, 42 anos, engenheira, morena, com três trabalhos distintos em cidades diferentes, afirma "emendar" de segunda a segunda. Circulando num mundo profissional dominado por homens, seu relato enfatiza mudanças, que também têm sido descritas acerca de mulheres que ao ocuparem posições de poder se "masculinizam":

Como tem poucos profissionais na minha área aqui em Goiás, eu sou muito exigida em tudo quanto é lugar (...) Eu fiquei muito conhecida, eu sei que meu trabalho é bom, eu não quero ser modesta, nem me enaltecer muito, eu procuro fazer a coisa bem feita e séria. Eu adquiri muito conhecimento na área de engenharia, então, não fiquei especialista num assunto somente, meu leque é muito amplo. Agora, engenheiro é muito exato, eles são agressivos, o mercado exige que você seja agressivo, então você vai se debandando pra esse lado também. Então, eu me policio muito. A área de exatas faz você ficar muito frio, muito calculista, principalmente quando você trabalha com empresário, com empreiteira. Aí eu procuro ler mais filosofia, direcionar mais meu lazer para o lado mais sentimental.

Como Mariah, para Cândida, 36 anos, professora universitária, branca, o ritmo exterior do trabalho, sobretudo o acadêmico, acessa outras necessidades, como por exemplo, o desejo de solidão, percebido como um caminho de volta, uma pausa necessária. Na época da entrevista, Cândida, se dividia 
"Remar o próprio barco"

entre três atividades diferentes e muito demandantes e enfatizou este "tempo para si":

Agora, o que mais está me fazendo falta é espaço próprio para leitura. Eu trabalho o dia inteiro, volto às sete da noite, então, chego detonada, não faço nenhum break, é muito puxado. Eu pergunto para os meus amigos que têm uma trajetória na academia, porque eu queria pelo menos o sábado e os domingos para mim, e a maioria me fala que escolhe o sábado ou o domingo, não tem nenhum no meu círculo que tenha livre os dois dias. Isso me assusta um pouco, porque eu estou sentindo falta de outro espaço para produzir sentido, eu preciso de espaço para ficar só, porque eu lido com muita gente [ênfase].

Essa falta é lamentada por outras duas professoras universitárias:

Eu ganho o quanto estou rendendo $e$, às vezes, não paro nem pro almoço. Sábado, às vezes, eu vou trabalhar. Se eu não tiver nada pra fazer eu vou curtir minha solidão porque senão a gente fica na fuga do trabalho e esquece a vida da gente, esquece a vida pessoal (Évora).

A minha vida está girando só em torno de serviço e isso não é saudável. O médico já perguntou onde eu estava, onde estava a pessoa, porque ele só estava vendo a profissional. Então, eu parei para pensar e falei "é verdade, tenho de abrir um espaço prá mim, porque para a vida profissional eu faço direto" (Laura).

É importante notar que as narrativas reiteram as separações dentro/fora, pessoal/privado e coletivo/público, comuns em alguns textos sociológicos que valorizam a esfera da intimidade como proteção contra um mundo inóspito. A esfera da intimidade, normalmente representada pela família nuclear - e aqui, pela solidão em casa (o "ninho") - se torna um antídoto contra a 
dispersão e a desagregação do mundo do trabalho, inscrito no espaço público (Lasch, 1991).

De modo geral, o trabalho é tão central para a maioria dessas mulheres "sós" que a possibilidade de perder o emprego ou a capacidade de trabalhar representa a perda de suas conquistas.

Ah, Deus me livre se eu não tiver meu emprego mais, como é que eu vou fazer as coisas que gosto? Sabe, me apavora um pouco não fazer as coisas que eu gosto, que eu quero, poder viajar, poder continuar tendo a vida que eu tenho. Eu acredito que está muito bem pra meus 29 anos, mas eu acho que eu posso melhorar mais, sempre estou buscando, minha vida gira em torno disso (Sarah).

Elas associam a perda da capacidade produtiva a uma noção de finitude, representada pelo adoecimento e pela velhice. O limite para a independência pelo trabalho é a velhice ou qualquer condição incapacitante, como enfatiza Laura: "a velhice começa quando eu não puder mais trabalhar, quando eu não puder fazer mais as coisas que eu faço sozinha". Mariah diz que não tem tempo para adoecer: "eu me vejo trabalhando até morrer, não quero parar nunca". Madalena recorre aos modelos que a ajudam a pensar na vida como uma possibilidade sempre aberta:

Tenho medo de doença, de não poder mais trabalhar. Uma coisa assim que me assustou outro dia foi que me chamaram de senhora e não gostei muito. Mas quando eu penso "pô já tô com quarenta, meu deus, ai meu deus, será que eu estou perdendo os melhores anos da minha vida?" Não, eu vejo o Roberto Marinho, ele lançou o jornal dele com 68, eu estou ainda na média (Madalena).

O tempo dedicado ao trabalho pode ser responsável por sentimentos de amargura e esgotamento. Então, outra dimensão 
"Remar o próprio barco"

desta separação ou da percepção de que a vida é consumida pelo trabalho - que reitera, de certo modo, a oposição público/privado - recoloca a questão da feminilidade enquanto lugar que requer proteção, o lugar do amor, como na narrativa de Sarah:

(...) para falar a verdade pra você, a felicidade para mim é..., o amor está em primeiro lugar, mais que o profissional, apesar dessa independência toda. Se eu achasse alguém que virasse pra mim e falasse assim, "você não precisa trabalhar", é claro que eu ia buscar de outra maneira me ocupar, enfim, mas eu queria, eu queria que alguém me protegesse. Estou cansada de proteger, de sempre ter que tomar frente, sempre que tomar todas as decisões.

$\mathrm{Na}$ sequência da entrevista, carregada de ambigüidade, Sarah reage à própria queixa, dizendo que se sentiria mal nessas situações, porque isso criaria dependência e enfatiza o desejo de construir algo junto: "quero alguém para a gente sair daqui $e$ conquistar uma coisa junto, mudar para um apartamento nosso, 'vamos fazer isso nós dois'..., ótimo, era isso que eu queria".

Como o sentido de independência está vinculado à independência financeira, conquistada no trabalho formal remunerado, o dinheiro é um elemento recorrente nas narrativas, sinalizando formas distintas de lidar com ele. Para a maioria das entrevistadas que explicam sua liberdade e autonomia pela via da independência econômica - "não devo a ninguém, ganho o meu dinheiro" -, ser dona do próprio dinheiro é como ter o destino em suas mãos, poder governá-lo, ter as rédeas da vida. Usando a metáfora do "remar o próprio barco"6, Sarah enfatiza a importância do dinheiro no sentido material e simbólico para sustentar a noção de autonomia na vida de mulheres "sós". Entretanto, nem sempre uma atitude arrojada em termos financeiros corresponde a uma sensação de segurança na vida

6 Como em "prefiro ser um espírito livre e remar eu mesma a minha canoa" (Luiza May Alcott [1868] apud Federman, 2001). 
pessoal. Évora afirma: "na vida pessoal eu sou um fracasso, na profissional eu sou excelente!", referindo-se à sua incrível capacidade de "fazer" dinheiro para a universidade e seu "descontrole" na vida pessoal, com os gastos excessivos. Às vezes, o dinheiro é apenas um veículo para obter o que se deseja, não significando muito em termos de status ou prestígio. Aquelas que tiveram alguma herança ou ajuda dos pais no início da carreira expressam uma atitude mais "hedonista" em relação ao dinheiro, enfatizando o consumo de produtos para si mesmas ou para pessoas queridas e próximas, e priorizando os "prazeres da vida" - "comer bem", viajar e ter acesso a bens culturais considerados fundamentais (música, literatura, arte).

Para a filósofa feminista estadunidense Nancy Hartsock, a possibilidade de ganhar e gerir o próprio dinheiro, realizando operações financeiras, faz parte do rol de conquistas feministas recentes. Comparando as novas gerações com a sua, dos anos 1960, a autora recorda a experiência pessoal vivida em uma época que restringia as operações financeiras à figura masculina:

Após o meu casamento, em 1965, eu solicitei por três vezes um cartão de crédito e todas as vezes eles "perdiam" minha solicitação. Finalmente, falei com alguém que me disse que eles não concediam cartões de crédito a esposas, mas que eles dariam uma linha de crédito em meu nome no cartão do meu marido. Eu era uma (presumidamente responsável) professora universitária! (Vogel, 2001).

A forma como cada entrevistada lida com a questão financeira emergiu em momentos distintos da entrevista, ao falar de seus perfis mais "gastadores" ou mais "poupadores", de seus êxitos profissionais e fracassos pessoais nesta área. Chama atenção o fato de algumas delas perceberem que ganhar dinheiro lhes confere um outro estatuto, tornando-as admiradas, invejadas, ainda que suas falas expressem também que o caminho percorrido não possui o glamour que aparenta. 
"Remar o próprio barco"

Eu acho que estou à frente de muita gente aí, viu. Eu te confesso que tem muita gente que queria estar assim do jeito que eu estou. Mas ninguém sabe o tanto que é difícil viver assim independente, com meu apartamento, meu carro, meu emprego, com as viagens que eu faço, todo mundo, "nossa... como eu queria...", mas ninguém sabe o tanto que foi difícil chegar onde eu estou, o tanto que é difícil manter, o tanto que é difícil...ah, é complicado (suspiro). Não sei te dizer... vou levando... (Sarah).

O dinheiro é o coroamento do trabalho e dá um sentido de ser/pertencer ao mundo, embora, do ponto de vista específico dos relacionamentos heterossexuais, para algumas signifique um complicador. Assim, certos padrões de comportamento ou regras de sociabilidade marcadas por gênero são revistas a partir do pressuposto do poder produzido pela independência financeira, emergindo a noção de "estar no controle".

Eu não tenho esse problema, se eu estou a fim de ir a um restaurante bom, eu vou, que eu tenho condições. (...) Eu não tenho problema, com homem eu sempre divido conta, eu não gosto de deixar o sujeito pagar sozinho, assim como eu não gosto de pagar sozinha, eu acho que tem que ser dividido. Mas, [se eu digo] "ah, vamos pra tal lugar", e ele diz "eu não posso, lá é muito caro", falo numa boa, "tranqüilo, tudo bem, pode deixar que fica por minha conta, eu banco". Mas em determinadas ocasiões, se o cara faz muita questão, eu também não me oponho, o cara pode pagar, contanto que eu não fique na mão dele (Mariah).

Para algumas entrevistadas, a independência financeira permite à "solteira" viver sem ter que se submeter, posição que se contrapõe ao casamento, percebido como um lugar de opressão $e$ gerador de laços de dependência financeira, entre outras. "Engolir sapo", "dar satisfações", "sujeitar-se" permeiam as narrativas sobre o casamento enquanto uma relação que oprime e subjuga a 
mulher, assim, ser "solteira" é não estar submetida ao domínio ou controle de um marido.

Veja bem, São Paulo e Goiânia têm suas diferenças. Como a A. [uma amiga] fala, aqui tem a instituição de esposa, mulheres que o único objetivo é o casamento, que é o fim de tudo. Eu posso entender na geração da minha mãe que tem mais de setenta anos, quantas vezes ela me falou, "ah, na sua idade eu já tinha dois filhos, na sua idade não sei o quê... você tem que arrumar um marido, casar". Mas na geração dela isso era importante (...) ela acreditava que o melhor pra mim seria o casamento. Hoje em dia ela não pensa mais assim, ela falou comigo, ela reconheceu que eu fiz o melhor da minha vida, porque eu não tenho que dar satisfação a ninguém, não tenho que engolir sapo, não tenho que me sujeitar a uma série de situações, porque eu ganho meu dinheiro, eu tenho minha vida. (...) Não é por ser mulher que eu tenho que seguir padrões, que eu tenho que me casar, ter filho, arrumar marido (Laura).

Laura reafirma a distância geracional entre ela e a mãe, explicitando que sua trajetória está permeada pelo contexto social e político que inaugurou uma outra forma de vida possível às mulheres, não centrada exclusivamente no matrimônio. Laura não fala de uma incompatibilidade entre carreira e matrimônio, como a contradição fundamental tão cara ao feminismo (Showalter, 1993; Brandon, 1990), ela expõe sua recusa a um tipo de aliança formal que sirva apenas para dar-lhe o status de casada.

\section{Entre carreira e casamento: ainda o impasse?}

A correlação entre educação, trabalho e estatuto conjugal no matrimônio heterossexual tem sido objeto de discussões na teoria social, em particular nos estudos de população, que focalizam o "desequilibrio" no mercado matrimonial, apontando 
"Remar o próprio barco"

uma relação de "desvantagem" para as mulheres, amplamente reforçada pela mídia. ${ }^{7}$

Entretanto, essa correlação não é recente. No passado, mulheres letradas que pretendiam se estabelecer profissionalmente e seguir carreira tinham que escolher entre a carreira e o matrimônio. Corrêa (2003) apresenta um fragmento dessa situação ao comentar a condição de celibatárias comum às precursoras da antropologia, passando pelas linhagens "femininas" da disciplina nas tradições inglesa, norte-americana e francesa. Embora, no decorrer da obra, Corrêa analise a condição de mulher solteira ou "sozinha" de algumas pioneiras no campo da antropologia e de outras ciências - o caso de Heloisa Alberto Torres -, sua descrição das linhagens remete à especificidade da condição de solteira entre as pioneiras que empreenderam trabalhos de campo, uma categoria separada das "esposas de antropólogos". A dedicação a uma profissão exigente, que demandava idas ao campo, muitas vezes regiões distantes e desconhecidas dos seus países de origem, era considerada uma "devoção" incompatível com o casamento:

Segundo uma tendência das profissionais da época, muitas dessas precursoras nunca se casaram: Audrey [Richards] deixou uma frase interessante sobre o assunto ("muitas de nós tinham a sensação de que éramos um grupo devotado especial, que não se casaria porque tínhamos coisas mais importantes a fazer. Havia a sensação de que uma moça que noivasse já estava quase deixando cair."); algumas parecem ter desejado casar-se (...); outras perceberam que, se o fizessem, abririam mão de uma independência que, na

7 As matérias sobre essa relação são recorrentes. Cf. Veja Especial Mulher (maio de 2006) - "A desconhecida lição das mulheres solteiras"-; "Pesquisa mostra que estudo é um estímulo ao progresso profissional feminino, mas não ao enlace matrimonial", Folha de S.Paulo, Cotidiano, 18/09/06. A capa de Veja (edição 1984, 29/11/06) traz a chamada "As chances de casar", anunciando o especial "A vida sem casamento", que mostra exatamente a mesma correlação "negativa" entre independência, letramento e casamento. Para uma visão ampliada desta discussão, ver Gonçalves (2007:cap. 2). 
época, não parecia ser compatível com o casamento. (...) Devoção parece ser uma palavra chave para definir algumas dessas mulheres, cujas biografias se têm notícia (Corrêa, 2003:192).

A análise de Corrêa coincide com informações contidas em biografias de mulheres ilustres - entre outras, Bertha Lutz no campo das ciências e Florence Nigthingale ${ }^{8}$ na enfermagem, ainda no século XIX -, elevadas à condição de heroínas por transpor fronteiras, servindo de modelo a outras mulheres (Vicinus, 1985).

Em épocas nas quais casamento e maternidade eram considerados "destino natural" da maioria das mulheres, a recusa explícita ao casamento heterossexual parecia uma estratégia planejada para construir novas formas de vida. Alguns estudos feministas que mencionam ou privilegiam abordagens sobre mulheres "solteiras" em outros períodos históricos ${ }^{9}$ demonstram que não casar possui significados distintos em épocas e contextos históricos específicos onde gênero, geração, "raça" e classe jogam um papel crucial. Nesse sentido, faz diferença pensar nos significados do celibato como resultado da não conciliação entre carreira e casamento (noção ainda vigente) ou conectado a objetivos políticos mais amplos (as pioneiras feministas do século XIX) e a defesa de um "estilo de vida" particular e voluntariamente eleito em função de necessidades subjetivas, como são apresentadas as "novas solteiras" do século XXI.

Zeldin (1994:102) indaga: "é inevitável que, embora fiquem sempre mais aventurosas e criem expectativas mais altas em relação à vida, as mulheres encontrem homens cada vez menos satisfatórios?". Quais seriam as dimensões da relação entre ser uma "mulher independente" $e$ as expectativas sociais $e$ pessoais face ao casamento, neste recorte da contemporaneidade?

8 Florence Nightingale é comparada a Joana D'Arc pelo seu heroísmo e renúncia (Vicinus, 1985).

9 Cf. Vicinus, 1985; Bennet and Froide, 1999; Holden, 2002, 2005; Showalter, 1993, 1989; Brandon, 1990; Lasser, 1988; Vicinus, 1985; Faderman, 2001. 
"Remar o próprio barco"

Embora a discussão contemporânea, sobretudo feminista, sobre a "solteirice" e o morar só privilegie a noção de escolha, algumas entrevistadas apontam diversos fatores que "explicam" sua "condição", às vezes, até mesmo estabelecendo nexos causais pelo fato de estarem "solteiras".

O ditado popular "sair das rédeas do pai e cair nas rédeas do marido" expressa uma visão do casamento heterossexual como lugar no qual se está "sob controle". No universo das entrevistadas há elementos comuns: em momentos específicos de suas trajetórias, elas buscaram escapar a alguma forma de controle que lhes afigurava opressivo ou desconfortável em suas casas paternas/maternas. Buscar um lugar de expressão individual, como sugere Sarah, passou primeiro pelo desejo de "sair dos mundinhos" restritivos representados pela permanência na casa dos pais.

Se para algumas mulheres sair de casa, estudar e trabalhar corresponde a um roteiro planejado, cujo destino final é o casamento, para as entrevistadas, o casamento em sua "estilística clássica" foi secundarizado por experiências de relacionamentos em outras modalidades. Algumas mulheres desejam casar um dia e "investem" nesta direção, outras, como Tália, 53 anos, funcionária pública, aposentada, morena, não empreendem esforço algum. Não é possível estabelecer uma relação de causalidade direta entre estes fatores, visto que outras mulheres, igualmente escolarizadas $e$ independentes financeiramente, se casam, constituem famílias, têm filhos e, mesmo não casando, não moram sozinhas. A questão está em compreender como - e não porque - determinadas trajetórias são construídas ao largo do casamento. Mesmo num universo pequeno, de doze mulheres, as expectativas quanto ao casamento $e$ as modalidades nas quais $o$ mesmo pode se realizar variam, mostrando que nenhum fator isolado (o individualismo das camadas médias, por exemplo) abarca esta análise, como ressalta Scott (2001). 
Eliane Gonçalves

\section{Intimidação ou marcas do gender gap}

As narrativas das entrevistas não endossam a velha dicotomia carreira/casamento, pelo fato único e simples da incompatibilidade entre ser/estar no mundo público e privado ao mesmo tempo. Dentre os argumentos apresentados por mulheres heterossexuais como "explicação" para o não-casamento - não investimento, foco na carreira, etc. - figuram a falta de homens adequados $e$ o medo que as mulheres independentes produzem neles, o gender gap, uma noção bastante corrente no senso comum.

Em O Segundo Sexo, Simone de Beauvoir (1980:459) declara ter ouvido de um jovem: "a mulher que não tem medo dos homens, amedronta-os", e também, de outros adultos: "tenho horror a que uma mulher tome a iniciativa" (Id.ib.:459). Respeitadas a distância e os contextos distintos, a frase do jovem na França dos anos 1940 repercute nos discursos atuais sobre as relações entre homens e mulheres, revelando que, do ponto de vista de gênero, no contexto cultural estudado, essas noções continuam produzindo ecos. Embora não tenha sido a tônica geral, a sensação de intimidação que uma mulher "só" provoca está marcada nas falas de algumas entrevistadas:

Pelo menos aqui, uma boa parte da população masculina tem medo de mulheres como eu, né? Olha, eu sou uma pessoa que ganho relativamente bem, se você for comparar à população brasileira, eu tenho um emprego estável, eu ganho relativamente bem, eu tenho um carro, não é carro do ano e tal, mas é um carro, tenho condições de viajar... Então, se você for ver o que nós somos em relação à população, e à população feminina do país, nós vivemos em uma posição privilegiada. Então, veja bem, o homem goiano, ou o homem mineiro, sei lá, ou o homem baiano, um dos que vivem aqui no Centro Oeste, como que ele lida com uma mulher assim? Uma mulher que tem uma boa 
"Remar o próprio barco"

educação, uma mulher que tem uma independência financeira, ele não pode dominar (Laura).

Proveniente da região Sudeste, Laura aponta a referência geográfica como um diferencial e considera os homens da região Centro-Oeste mais rudes e menos habilitados a lidar com mulheres como ela. Considerações semelhantes às de Jussara, funcionária pública, 34 anos, morena, sobre a realidade local:

Os homens lidam mal com o fato de eu morar só. Eles têm medo de mim. Eu não sou a primeira a falar isso, eu já vi outras falando, que moram sós. Homem gosta de mulher dependente. Por exemplo, esse meu mesmo [exnamorado], eu analiso assim, por que ele não toma uma atitude? Porque ele acha que não vai conseguir me controlar, que eu sou independente demais, que ele queria uma pessoa assim, que ele pudesse controlar, que dependesse dele... Não, eu sou uma pessoa que trabalho fora, não dependo e tal, e isso dá medo.

Ambas enfatizam o caráter de dominação, controle, que um homem pode exercer sobre uma mulher que não seja independente. Suas noções expressam o "velho" padrão de relações heterossexuais, nas quais se presumem hierarquias que têm a função de estabilizar a relação na suposta fórmula da complementaridade. Vários trabalhos de Mirian Goldenberg tratam dessa problemática. Em Sobre a invenção do casal, respondendo pela lógica do gender gap, à pergunta "por que os relacionamentos naufragam?", a autora diz:

Uma resposta fácil para esta dificuldade de convivência é a maior autonomia e independência feminina, relativamente recentes, resultado da sua imersão no mercado de trabalho. As mulheres passaram a exigir muito mais de seus relacionamentos afetivo-sexuais. Quanto mais independente economicamente é a mulher, mais exigente 
ela se torna com o seu parceiro amoroso. O quadro atual do trabalho feminino demonstra que não são poucas as mulheres que podem "escolher" livremente um relacionamento amoroso de acordo com os seus desejos. (...) Preferem viver sós do que mal acompanhadas e têm mais medo da solidão a dois do que da vida sem um parceiro amoroso (Goldenberg, 2001:5).

A noção de independência continua presente em outras situações vividas no âmbito da sociabilidade e remetem à luta feminista pela igualdade em todos os planos, mas colide com algumas expectativas sociais. Embora referidas a distintos contextos de classe, entre outros, as relações entre homens $e$ mulheres foram afetadas, na vida social, pela novidade da igualdade. Assim, algumas mulheres expressam ambiguidade em suas expectativas de igualdade ao mencionar situações sociais nas quais esperam um comportamento diferente, mais "cavalheiro" dos homens.

A manutenção de determinados "privilégios", de uma educação diferenciada, em uma realidade de maior independência econômica parece ser um paradoxo e tem sido recorrentemente caracterizada como uma dificuldade de ambos, homens e mulheres, para lidar com novas situações sociais. Vale notar que essa interpretação não é propriamente nova, uma vez que aparece com freqüência nas análises sobre a emergência do feminismo como um movimento social no final do século XIX. A "nova mulher", retratada por historiadoras e críticas literárias feministas (Showalter, 1993, 1989; Brandon, 1990; Vicinus, 1985; Bennet and Froide, 1999) está recorrentemente às voltas com as dificuldades de relacionamento com o "velho homem".

\section{Elas “pagam um preço” - considerações finais}

Para Beck e Beck-Gernsheim (1995:63), as mulheres "solteiras", ricas ou pobres, "pagam um preço". Comparando "solteiras" e separadas com poucos recursos ("mulheres sem 
"Remar o próprio barco"

marido") e mulheres independentes, os autores argumentam que "na outra extremidade da escala, há outro problema emergindo, afetando mulheres que, seguindo uma carreira independente, em muitos casos pagam um alto preço, a solidão da mulher profissional de sucesso". Os autores presumem que a heterossexualidade conjugal é a base para a felicidade, pois a mulher solteira tem sido o alvo das terapias modernas para suas queixas de necessidades não preenchidas. É praticamente impensável projetar esta análise social para as "perdas masculinas" em relação ao mundo doméstico, ao cuidado com as crianças ou à falta de intimidade que uma relação heterossexual pode vir a proporcionar.

De outro lado, a contundente crítica feminista desenvolvida por Stacey (1986) ao modelo "familista", dominante em algumas produções teóricas dentro do feminismo ${ }^{10}$, decepciona ao analisar o "celibato involuntário" das mulheres como uma das conseqüências dos caminhos percorridos pelas feministas da segunda onda em seu ataque à família e à maternidade. Segundo a autora (id.ib.:237), as feministas dos anos 1970 queriam evitar o casamento e a maternidade para se libertarem da escravidão doméstica e lutavam pela igualdade de gênero. Um dos resultados decorrentes do acirramento entre escolher viver de modo independente e casar e ser mãe, foi um "trauma pessoal" ocorrido em três dimensões: solteirice involuntária, ausência involuntária de filhos e a maternidade solteira (involuntary singlehood, involuntary childlessness and single motherhood). Essa busca pelas origens do feminismo e seus possíveis "fracassos" indicam, como sugere Butler, que a "solteirice", tal como apresentada, se torna uma identidade designada como origem e causa quando, de fato, é "efeito de instituições, práticas e discursos com múltiplos e difusos

${ }^{10} \mathrm{O}$ artigo de Stacey (1986) analisa o pressuposto "familista" ou pró-family em três livros de autoras feministas publicados nos anos 1980: Betty Friedan (The second stage), Jean B. Elshtain (Public Man, Private Woman) e Germaine Greer (Sex and Destiny). 
pontos de origem" (Butler, 1999:xxix). Por que a "solteirice" e a não-maternidade seriam, desde sempre, "involuntárias"?

Recuando um pouco na história, Faderman reafirma o nexo entre perseguir uma carreira e permanecer solteira como a condição da maioria das mulheres que trilharam, no passado, o caminho da independência pela via do trabalho, nos Estados Unidos e na Europa:

Considerando o grande compromisso profissional que deve ter sido necessário a uma pioneira do século XIX para alcançar reconhecimento numa determinada carreira, não surpreende que de 1470 biografias das mais distintas e célebres mulheres desta época, estudadas por Frances Williard e Mary Livermore, em 1893, mais de 25\% delas eram solteiras, um terço das que casaram eram viúvas que permaneceram solteiras; em outras palavras, mais da metade passou a maior parte da vida sem se casar. (...) e as que fizeram $\mathrm{PhD}$ em universidades americanas entre $1877 \mathrm{e}$ 1924, três quartos não se casaram (Faderman, 2001:186-187).

Desde as principais conquistas - voto, educação, trabalho remunerado, liberdade sexual e maior abertura no mundo político - ainda persistem noções que relacionam a independência das mulheres a "sacrifício e perdas", pagando um alto preço pela "diferença" de sua "experiência". Como lembra Joan Scott (1992:25), não basta reconhecer as diferenças, mas compreender como são estabelecidas e como operam na constituição das subjetividades. A naturalização da necessidade do par e do casamento no contexto de uma matriz heterossexual e reprodutiva ainda coloca a "solteira" que mora só como uma "outra", cuja alteridade é definida pela mulher "casada", silenciando sobre outras possibilidades. Mas, como afirma Rubin (2003:167),

O caráter persistente de algumas coisas leva as pessoas a acharem que elas não são geradas socialmente. Mas o tipo de mudança social que estamos falando requer muito 
"Remar o próprio barco"

tempo e o período de tempo que estivemos tentando essa mudança é incrivelmente pequeno.

\section{Referências bibliográficas}

AMORIM, Nádia Fernanda. O estigma da mulher solteira. Maceió, UFAL, 1992.

BARRET, Michele and MACINTOSH, Mary. The anti-social family. London, Verso, 1991 [1983].

BASSANEZI, Carla. Mulheres dos anos dourados. In: Del PRIORI, Mary e BASSANEZI, Carla. (orgs.) História das Mulheres no Brasil. São Paulo, Unesp, 2000, pp.607-639.

BEAUVOIR, Simone. O segundo sexo. Rio de Janeiro, Nova Fronteira, 1980 [1949].

BECK, Ulrich and BECK-GERNSHEIM, Elisabeth. The normal chaos of love. Cambridge, MA, Polity Press, 1995.

BenNetT, Judith. and Froide, Amy. A Singular Past. In: BennetT, J. and Froide, A. (orgs.) Singlewomen in the European Past, 1250-1800. Philadelphia, Penn, 1999, pp.1-37.

BILAC, Elizabeth Dória. Apresentação. Boletim Mulher \& Trabalho (13), São Paulo, Fundação Seade, 2002, pp.3-5.

BRANDON, Ruth. The new women and the old men: Love, sex and the woman question. London, Norton and Company, 1990.

BRUSCHINI, Cristina. Gênero e trabalho no Brasil: novas conquistas ou persistência e discriminação? In: RocHA, Maria Isabel Baltar da. (org.) Trabalho e Gênero: mudanças, permanências e desafios. São Paulo, Editora 34, 2000, pp.13-58.

e PuPPIN, Andrea B. Trabalho de mulheres executivas no Brasil no final do século XX. Cadernos de Pesquisa, vol. 34 (121), São Paulo, Fundação Carlos Chagas, 2004, pp.105-138.

BuTLER, Judith. Gender Trouble. 10 a ed. New York, Routlegde, 1999.

BYRNE, Anne. Singular Identities: Managing stigma, resisting voices. Women's Studies Review, vol. 7, 2000, pp.13-24.

CORRÊA, Mariza. Antropólogas \& Antropologia. Belo Horizonte, Editora UFMG, 2003. 
Do feminismo aos estudos de gênero no Brasil: um exemplo pessoal. Cadernos Pagu (16), Campinas-SP, Núcleo de Estudos de Gênero - Pagu/Unicamp, 2001, pp.13-30.

DURHAM, Eunice. Família e reprodução humana. In: FRANCHETO, Bruna, CAVAlCANTI; Maria Laura V.C. e HEILBORN, Maria Luisa. (orgs.) Perspectivas Antropológicas da Mulher. Rio de Janeiro, Zahar Editores, 1983, pp.13-45.

FADERMAN, Lilian. Surpassing the love of men. New York, Morrow, 2001 [1980].

FRIEDAN, Betty. The Feminine Mystique. New York, WW Norton \& Company, 1963.

GIDDENS, Anthony. A vida em uma sociedade pós-tradicional. In: GIDDENS, A.; BECK, Ulrich and LASH, Scot. Modernização Reflexiva. São Paulo, Editora da Unesp, 1995, pp.73-134.

GolDENBERG, Miriam. Sobre a invenção do casal. Estudos e Pesquisas em Psicologia, vol. 1, $\mathrm{n}^{\circ}$ 1, Rio de Janeiro, UERJ, 2001, pp.89-104. Disponível em www.miriangoldenberg.com [acesso em setembro de 2006, pp.1-9].

GONÇALVES, Eliane. Vidas no singular: noções sobre mulheres 'só' no Brasil contemporâneo. Tese de doutorado em Ciências Sociais área de gênero, IFCH/Unicamp, 2007.

GoRDON, Tuula. Single Women: on the margins? New York University Press, 1994.

HIRATA, Helena. Salariado, precariedade, exclusão? Trabalho e relações sociais de sexo-gênero: uma perspectiva internacional. OLIVEIRA, Maria Coleta. (org.) Demografia da exclusão social. Campinas-SP, Editora da Unicamp, 2001, pp. 105-118.

HOLDEN, Katherine. Nature takes no notice of morality: singleness and married love in interwar Britain. Women's History Review, vol. 11 (3), 2002, pp.481-503.

. Imaginary widows: spinsters, marriage, and the "lost generation" in Britain after the great war. Journal of Family History, vol. 30, no 4, London, Sage Publications, October 2005, pp.388409. 
"Remar o próprio barco"

KERGOAT, Daniele. División sexual del trabajoy e relaciones sociales entre los sexos. In: HIRATA, Helena et alii. (orgs.) Diccionario critico del feminismo. Madrid, Editorial Síntesis, 2002, pp.66-75.

KERGOAT, Priska. Ofício, profesión, trabajo. In: HIRATA, Helena et alii. (orgs.) Diccionario critico del feminismo. Madrid, Editorial Síntesis, 2002, pp.169-172.

KLEIMAM, Ângela. Os significados do letramento: uma nova perspectiva sobre a prática social da escrita. Campinas-SP, Mercado de Letras, 1995.

LASCH, Christopher. Refúgio num mundo sem coração. São Paulo, Paz e Terra, 1991.

LASSER, Carol. Let us be sisters forever. Signs, vol. 14(1), Chicago, The University of Chicago, 1988, pp.158-179.

LOBO, Elisabeth Souza. O trabalho como linguagem: o gênero do trabalho. In: COSTA, Albertina de Olveira e BRUSCHINI, Cristina. (orgs.) Uma questão de gênero. Rio de Janeiro, Rosa dos Tempos, 1992, pp.252-265.

LOURO, Guacira Lopes. Gênero, Sexualidade e Educação. Petrópolis, Vozes, 1997.

MILLET, Kate. Sexual politics. New York, Doubleday, 1970.

NERI, Marcelo. Economia, sexo e casamento. São Paulo, FGV, 2004.

NiCHOLSON, Linda. The contemporary women's movement. In: Gender and History. Columbia University Press, 1986, pp.17-42.

PICOT, Genevieve. Profesión. In: HIRATA, Helena et alii. (orgs.) Diccionario critico del feminismo. Madrid, Editorial Síntesis, 2002, pp.172-175.

PINTO, Joana Plaza. (org.) Entrelinhas - Para ler e escrever sobre sexo, prazer e poder. Goiânia, Grupo Transas do Corpo, 2004.

PISCITELLI, Adriana. Re-criando a (categoria) mulher? Textos Didáticos, $n^{\circ} 48$ - Algranti, Leila Mezan. (org.) A Prática Feminista e o Conceito de Gênero -, Campinas-SP, IFCH/Unicamp, novembro de 2002, pp.7-42.

ROSALDO, Michelle. A mulher, a cultura e a sociedade: uma revisão teórica. In: ROSALDO, Michelle e LAMPHERE, Loise. (orgs.) A mulher, a cultura e a sociedade. Rio de Janeiro, Paz e Terra, 1979, pp.33-64. 
ROSEMBERG, Fúlvia. Educação formal, mulher e gênero no Brasil contemporâneo. Estudos Feministas, vol. 9 (2), Florianópolis, UFSC, 2001, pp.515-540.

- Educação formal e mulher: um balanço parcial da bibliografia. In: COSTA, Albertina Oliveira e BRUSCHINI, Cristina. (orgs.) Uma questão de gênero. Rio de Janeiro, Rosa dos Tempos, 1992, pp.151-182.

RuBIN, Gayle. Tráfico sexual - entrevista. Cadernos Pagu (21), Campinas-SP, Núcleo de Estudos de Gênero - Pagu/Unicamp, 2003, pp.157-209.

RUPP, Leila. Sexualidade e Política no começo do século XX: o caso do movimento internacional de mulheres. Labrys estudos feministas (1/2), jul/dez de 2002. Disponível em www.labrys.unb.br [acesso em 12/2005].

SARTI, Cynthia A. A sedução da igualdade: trabalho, gênero e classe. In: SCHPUN, Mônica Raisa. (org.) Gênero sem fronteiras. Florianópolis, Editora Mulheres, 1997, pp.153-168.

SCOTT, Joan. Experience. In: BUTLER, Judith and SCOTT, Joan. (eds.) Feminists theorize the political. New York, Routledge, 1992, pp.2240.

ScotT, Russel Parry. Demografia e Antropologia: a favor da articulação de pesquisas no Nordeste. UFPE, 2001. Disponível em http://www.fundaj.gov.br [acesso em 06/02/2006].

SHOWALTER, Elaine. Anarquia Sexual. Rio de Janeiro, Rocco, 1993.

. These modern women: autobiographical essays from the twenties. New York, The Feminist Press, 1989.

SIMPSON, Roona. Contemporary spinsterhood in Britain: gender, partnership status and social change. Thesis submitted for the $\mathrm{PhD}$ degree, University of London, 2005.

. Contemporary Spinsters in the new millennium: changing notions of familiy and kinship. New worker paper series (10), London School of Economics/Gender Institute, July 2003, pp.1-30

STACEY, Judith. Are women afraid to leave home? In: MITCHEL, Juliet. \& OAKLEY, Ann. What is Feminism?. Oxford-UK, Blackwell Publishers, 1986, pp.208-237. 
"Remar o próprio barco"

TRIMBERGER, Kay E. The new single woman. Boston, MA, Beacon Press, 2005.

VAITSMAN, Jeni. Flexíveis e Plurais. Rio de Janeiro, Rocco, 1994.

VALCÁRCEL, Amélia. O feminismo é uma teoria política ou uma ética? Debate Feminista: Feminismo e Cidadania. São Paulo, Cia Melhoramentos, 1999, pp.206-222 [edição especial em português de Debate Feminista, México].

VeLHO, Gilberto. Subjetividade e sociedade. Rio de Janeiro, Jorge Zahar Editor, 2002.

VICINUS, Martha. Independent Women: work and community for single women, 1850-1920. Chicago, The University of Chicago, 1985.

Vogel, Traci. Push Anywhere: An Interview with Nancy Hartsock. The Stranger, Seatle, 03/29/2001.

Woolf, Virgínia. Um teto todo seu. Rio de Janeiro, Nova Fronteira, 1985.

ZELDIN, Theodore. Uma história íntima da humanidade. Rio de Janeiro, Record, 1994. 